\title{
Новий доступ у хірургії дистального плеча
}

\begin{abstract}
Мета роботи: розробка найоптимальнішого доступу до ліктьового суглоба для репозиції та фіксації переломів головчастого підвищення плечової кістки.

Проведено аналіз карт стаціонарного хворого: 98 пацієнтів (42 чоловіки, 56 жінок) з переломами дистального епіметафіза плечової кістки. 3 переднього доступу прооперовано 9 пацієнтів, із заднього - 47, з бокового - 38, 3 комбінованих доступів - 4 . 15 \% усіх пацієнтів потребували повторних реконструктивних операційних втручань для усунення незадовільних результатів. Запропонований нами новий спосіб операційного лікування уламкових внутрішньосуглобових переломів дистального епіметафіза правої плечової кістки за класифікацією міжнародної асоціації остеосинтезу (13С1, 13С2, 13С3) застосували у 7 пацієнтів. Отримано патент на корисну модель нового доступу до плечового суглоба № 134427 від 10.05.2019.

Запропонований нами доступ при лікуванні внутрішньосуглобових переломів дистального епіметафіза плечової кістки дозволяє зберегти точки прикріплення груп м’язів, мінімізувати ризики ушкоджень нервових та судинних структур, забезпечити скорочення термінів непрацездатності та хороші віддаленні результати.
\end{abstract}

Ключові слова: ліктьовий суглоб; дистальний епіметафіз; плечова кістка; доступ; перелом; остеосинтез.

Ліктьовій суглоб класифікують як складний артикулюючий комплекс, який, після плечового суглоба, є продовженням ланцюга посилення дрібної моторики у напрямку дисталізації до кисті та пальців. Головчасте підвищення відіграє важливу роль у функціонуванні ліктьового суглоба, оскільки забезпечує один з трьох ступенів свободи - ротаційну мобільність. Переломи дистального епіметафіза плечової кістки є складними для хірургічного лікування, оскільки потребують ідеальної репозиції та стабільної фіксації. Незадовільна функція ліктьового суглоба, особливо дефіцит згинання, призводить до значних труднощів у самообслуговуванні та професійній діяльності пацієнтів у післяопераційному періоді.

Частка незадовільних віддалених результатів після хірургічного лікування переломів дистального епіметафіза плечової кістки залишається високою (Sen R. K., Tripahty S. K., 2013).

Внутрішньосуглобові переломи для отримання найкращого функціонального результату повинні бути максимально точно зіставлені. Фіксація повинна бути стабільною, оскільки реабілітація має починатися в максимально короткі терміни.

На даний час існує декілька методів доступу до ліктьового суглоба при внутрішньосуглобових переломах. Усі вони класифікуються на передні, задні, бокові та їх комбінації. Задні доступи за Фарабефом, Кемпбелом, Кісельбаумом проходять через триголовий м'яз як з його відсіченням, так і без відсічення.

Складність переднього доступу в проекції кубітальної ямки пов'язана з прецизійною роботою із виділення судинно-невральних структур із можливою їх травматизацією.
Найбільш вживаним серед зовнішніх доступів $є$ доступ за Кохером, при якому розріз проводять у проекції верхівки зовнішнього надвиростка плечової кістки. Загальне сухожилля розгиначів відсепаровують від місця прикріплення та відводять, отримуючи доступ до капсули суглоба.

Ці методики мають ряд недоліків, оскільки не дозволяють повною мірою візуалізувати місце ушкодження, особливо при багатоуламкових переломах. У процесі доступу проводиться препарування значного м'язового та сухожилкового масиву, що в подальшому збільшує термін іммобілізації та реабілітації. Внаслідок близького проходження заднього міжкісткового нерва передпліччя існує небезпека його пошкодження. Все це вмотивовує до розробки нових, більш ефективних та щадних доступів до ліктьового суглоба.

Мета роботи: розробка найоптимальнішого доступу до ліктьового суглоба для репозиції та фіксації переломів головчастого підвищення плечової кістки.

Ми провели аналіз карт стаціонарого хворого 98 (42 чоловіків, 56 жінок) пацієнтів з переломами дистального епіметафіза плечової кістки, яким проводилось оперативне лікування. 3 переднього доступу прооперовано 9 пацієнтів, із заднього - 47, з бокового - 38, з комбінованих доступів - 4. Слід зазначити, що 15 \% усіх пацієнтів потребували повторних реконструктивних операційних втручань для усунення незадовільних результатів у віддаленому післяопераційному періоді. Серед них були контрактури, гетеротопічні осифікати, міграції металофіксаторів та вторинні комперсійні нейропатії.

Для вирішення та уникнення вказаних проблем нами запропонований хірургічний доступ до лік- 
тьового суглоба, який забезпечує збереження анатомічних точок прикріплення м'язів-розгиначів, мінімізує ризик ятрогенного пошкодження нервових структур, створює найкращу візуалізацію місця перелому. Запропонований нами новий спосіб застосували на 7 пацієнтах, оперованих з приводу уламкових внутрішньосуглобових переломів дистального епіметафіза правої плечової кістки за класифікацією Міжнародної асоціації остеосинтезу (13С1, 13С2, 13С3). Розробку нового доступу закріплено отриманням патенту на корисну модель № 134427 від 10.05.2019. Хірургічний доступ для фіксації перелому головчастого підвищення плечової кістки проводиться шляхом розрізу шкірних покривів по латеральній поверхні плеча. Розріз проводять дистально по латеральній поверхні плеча, прямуючи до головки і шийки променевої кістки, розсікають фасцію по лінії шкірного розрізу. Далі розріз продовжують між черевцем ліктьового розгинача кисті та черевцем ліктього м'яза, звільняють місце прикріплення плечопроменевого м'яза, променевого розгинача та трицепса плеча. Запропонований нами метод відрізняється тим, що паралельно до осі плечової кістки проводиться остеотомія латерального надвиростка вище прикріплення латеральної колатеральної зв'язки без поширення зони остеотомії на суглобову поверхню. Остеотомічно відділену частину кістки латерального надвиростка відводять в сторону і в ділянку зрізу перпендикулярно (чи під необхідним кутом) до осі плечової кістки вводять фіксуючі гвинти, які скріплюють кісткові уламки головчастого підвищення. Остеосинтез здійснюють згідно з усіма правилами оперативного лікування внутрішньосуглобових переломів. Після закінчення реконструкції суглобових поверхонь частину латерального надвиростка репонують по зоні остеотомії і фіксують стабільно-функціональним методом.

Операцію проводять після знекровлення під джгутом. Приблизний час операції - 60 хв. Для зручності передоперційного моделювання плану втручання використовували, окрім рентгенографії у стандартних проекціях, дані комп’ютерної томографії.

Розріз в проекції латерального надвиростка до 10 см як при стандартному бічному доступі за Кохером.

Прилеглі тканини розшаровуються до візуалізації латерального надвиростка плечової кістки, виконується капсулотомія.

Остеотомія проводиться для отримання можливості відведення супінатора та короткого променевого розгинача кисті разом з блоком латеральної колатеральної зв’язки.
Візуалізація перелому здійснюється після проведеної капсулотомії з остеотомією. Виконують металоостеосинтез блоку та головчатого підвищення (рис. 1). Обов’язковим є динамічний інтраопераційний рентгенконтроль С-аркою (рис. 2).

Виконується металоостеосинтез латерального виростка за допомогою гвинтів Герберта, якщо потрібно зафіксувати волярний фрагмент головчастого підвищення, або спонгіозних гвинтів при достатній величині фрагменту головчастого підвищення. Латеральний надвиросток фіксується за допомогою блокуючої мікропластини для можливості ранньої функції у ліктьовому суглобі.

Жодних ускладнень в ранньому та пізньому післяопераційному періоді не зазначали. Ранню реабілітацію розпочинали через години після проведеного операційного лікування під прикриттям

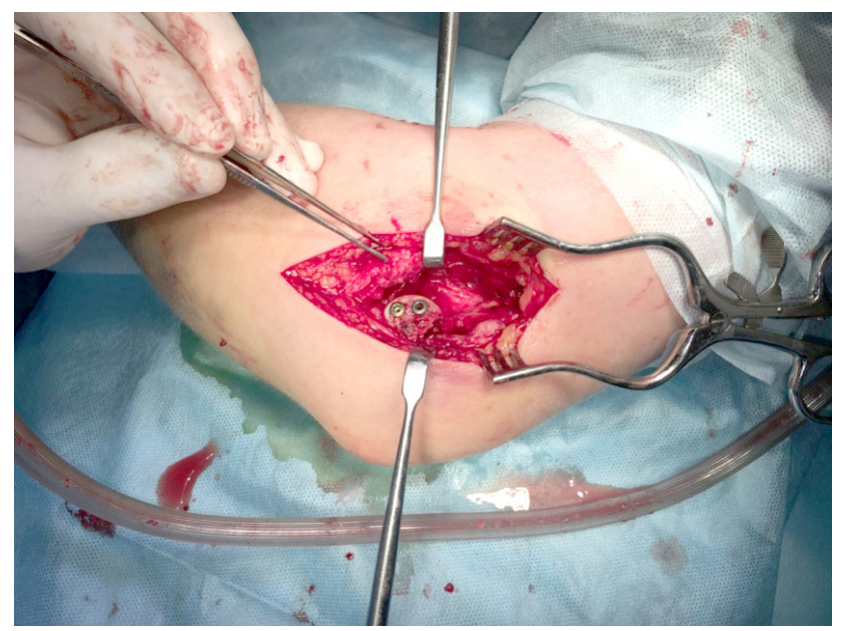

Рис. 1. Металоостеосинтез блоку та головчастого підвищення.

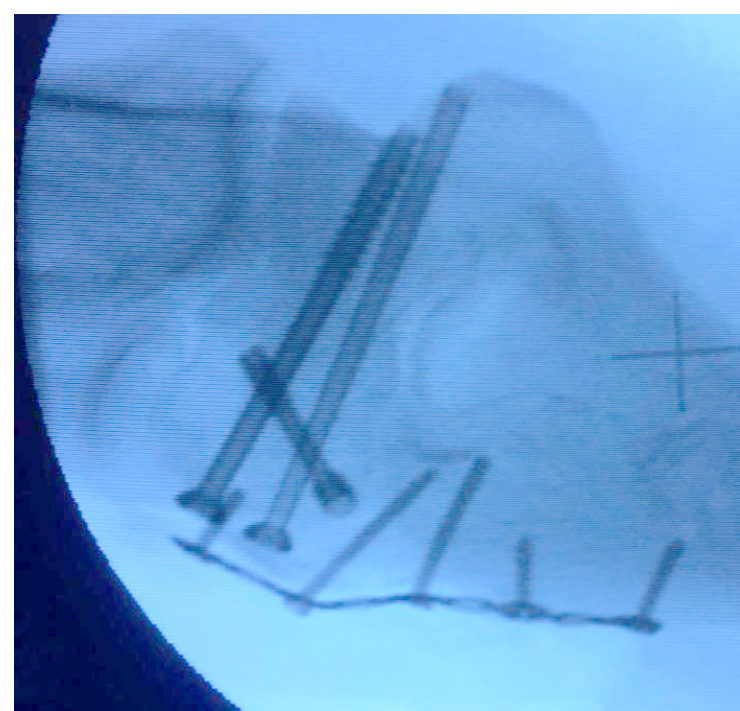

Рис. 2. Інтраопераційний рентгенконтроль С-аркою. 
пролонгованої регіонарної анестезії та постановкою периневрального катетера.

Функціональні результати ліктьового суглоба через 5 місяців активної реабілітації розцінювались як відмінні.

Запропонований доступ при лікування внутрішньосуглобових переломів дистального епіме- тафізу плечової кістки є найбільш фізіологічним, оскільки дозволяє зберегти точки прикріплення груп м'язів, мінімізувати ризики ушкоджень нервових та судинних структур, що позитивно відображається на скороченні термінів непрацездатності та дозволяє забезпечити хороші віддаленні результати.

\section{СПИСОК ЛІТЕРАТУРИ}

1. Рюди Т. П. АО - Принципы лечения переломов / Т. П. Рюди, Р.Э. Бакли, К. Г. Моран ; пер. А. А. Ситник. - 2-е изд. Берлин : Вассамедиа, 2013. - 638 с.

2. Повреждения локтевого сустава : руководство / В. И. Зоря,

А. В. Бабовников. - Москва : ГЭОТАР-Медиа , 2010.- 464 с.

3. Coronal shear fracture of the humeral trochlea / R. K. Sen,

S. K. Tripahty, T. Goyal, S. Aggarwal // J. Orthop. Surg. - 2013. - Vol . 21 (1). - P. 82-86.

4. Singh A. P. Coronal shear fractures of distalhumerus: diagnostic and treatment protocols / A. P. Singh, A. P. Singh // World J. Orthop. - 2015. - Vol. 6 (11). - P. 867-876.

5. Chhabra M. Orthopaedic surgical approaches. $2^{\text {nd }}$ edition / M. Chhabra. - ELSEVIER. - 2015.

6. Management of distal humeral coronal shear fractures / S. S. Yari, N. L. Bowers, M. A. Craig [et al.] // World J. Clin. Cases. - 2015. - Vol. 3 (5). - P. 405-417.

\section{REFERENCES}

1. Ryudi,T.P., Bakli, R.E., \& Moran, K.G. (2013). AO - Printsypy lecheniya perelomov [AO - principles of fracture treatment]. Sitnik, A.A. (Trans.). Berlin: Vassamedia [in Russian].

2. Zorya, V.I., \& Babovnikov, A.V. (2010). Povrezhdeniya loktevogo sustava [Elbow joint injuries]. Moscow: GEOTAR-Media [in Russian].

3. Sen, R.K., Tripahty, S.K, Goyal,T., \& Aggarwal, S. (2013). Coronal shear fracture of the humeral trochlea. J. Orthop. Surg., 21 (1), 82-86.

4. Singh, A.P. \& Singh, A.P. (2015). Coronal shear fractures of distalhumerus: diagnostic and treatment protocols. World J. Orthop., 6 (11), 867-876.

5. Chhabra, M. (2015). Orthopaedic surgical approaches. $2^{\text {nd }}$ edition. ELSEVIER.

6. Yari, S.S., Bowers, N.L., Craig, M.A., \& Lee, M.R. (2015). Management of distal humeral coronal shear fractures. World $J$. Clin. Cases, 3 (5), 405-417.

Отримано 02.04.2020

\section{A NEW APPROACH IN DISTAL SHOULDER SURGERY}

The aim of the work: to develop the most optimal access to the elbow joint for repositioning and fixation of fractures of the capitulum of the humerus.

The analysis of inpatient cards was performed: 98 patients (42 men, 56 women) with fractures of the distal epimetaphysis of the humerus. 9 patients underwent anterior access, 47 from the posterior, 38 from the lateral, and 4 from the combined accesses. $15 \%$ of all patients required secondary reconstructive surgical interventions to eliminate unsatisfactory results.

Our proposed new method of surgical treatment of fragmentary intra-articular fractures of the distal epimetaphysis of the right humerus according to the classification of the International Association of Osteosynthesis (13C1,13C2,13C3) was used in 7 patients. A patent for a utility model of new access to the shoulder joint No. 134427 of May 10, 2019 was received.

Our proposed approach in the treatment of intra-articular fractures of the distal epimetaphysis of the humerus allows you to maintain the attachment points of muscle groups, minimize the risk of damage to nerve and vascular structures, provide reduced incapacity and good long-term results.

Key words: elbow joint; distat epimetaphysis; humerus; access; fracture; osteosynthesis. 


\section{ПОВІДОМЛЕННЯ}

Ю. Р. ТУГАРОВ, А. В. ЯВОРСКИЙ, А. В. ДУМАНЕЦ, А. И. КУЛЯНДА, М. И. КОСТЫШИН, О. Т. ЦЫБИК

МЦ “Ортоклиника”, Тернополь

\section{НОВЫЙ ДОСТУП В ХИРУРГИИ ДИСТАЛЬНОГО П.ЛЕЧА}

Цель работы: разработка оптимального доступа к локтевому суставу для репозиции и фиксации переломов головчатого возвышения плечевой кости.

Проведен анализ карт стационарного больного: 98 пациентов (42 мужчины, 56 женщин) с переломами дистального эпиметафиза плечевой кости. С переднего доступа прооперировано 9 пациентов, с заднего - 47, из бокового - 38, из комбинированных доступов - 4. 15 \% всех пациентов нуждались в повторных реконструктивных оперативных вмешательств для устранения неудовлетворительных результатов.

Предложенный нами новый способ операционного лечения осколчатых внутрисуставных переломов дистального эпиметафиза правой плечевой кости по классификации международной ассоциации остеосинтеза (13C1,13С2,13С3) применили у 7 пациентов. Получен патент на полезную модель нового доступа к плечевому суставу № 134427 от 10.05.2019.

Предложенный нами доступ при лечении внутрисуставных переломов дистального эпиметафиза плечевой кости позволяет сохранить точки прикрепления групп мышц, минимизировать риски повреждений нервных и сосудистых структур, обеспечить сокращение сроков нетрудоспособности и хорошие отдаленные результаты.

Ключевые слова: локтевой сустав; дистальный эпиметафиз; плечевая кость; доступ; перелом; остеосинтез. 